Received: 5 July 2017

Accepted: 9 October 2017

Published online: 25 October 2017

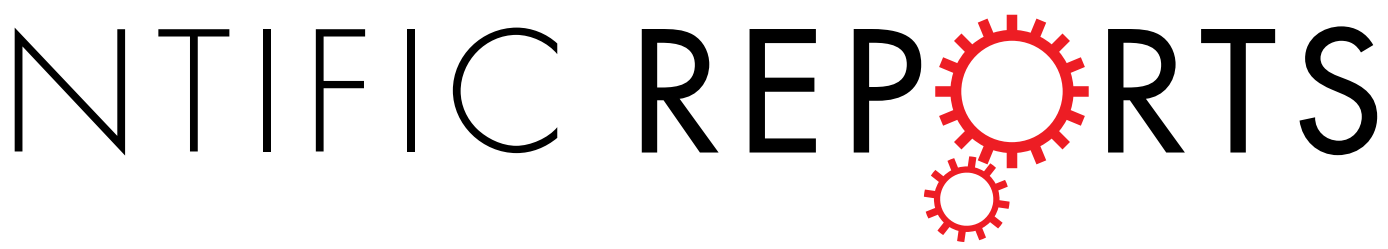

\title{
New Routes for Refinery of Biogenic Platform Chemicals Catalyzed by Cerium Oxide-supported Ruthenium Nanoparticles in Water
}

\author{
Tomoo Mizugaki ${ }^{1}$, Keito Togo ${ }^{1}$, Zen Maeno ${ }^{1}$, Takato Mitsudome ${ }^{1}$, Koichiro Jitsukawa ${ }^{1}$ \& \\ Kiyotomi Kaneda $\mathbb{B}^{1,2}$
}

Highly selective hydrogenative carbon-carbon bond scission of biomass-derived platform oxygenates was achieved with a cerium oxide-supported ruthenium nanoparticle catalyst in water. The present catalyst enabled the selective cleavage of carbon-carbon $\sigma$ bonds adjacent to carboxyl, ester, and hydroxymethyl groups, opening new eight synthetic routes to valuable chemicals from biomass derivatives. The high selectivity for such carbon-carbon bond scission over carbon-oxygen bonds was attributed to the multiple catalytic roles of the Ru nanoparticles assisted by the in situ formed $\mathrm{Ce}(\mathrm{OH})_{3}$.

Current requirements to reduce carbon dioxide emissions have been the driving force for biorefinery utilizing renewable resources, such as plant biomass, as carbon-neutral feedstocks for commodity chemicals ${ }^{1-7}$. The development of highly efficient catalytic methods would greatly accelerate the utilization of biomass feedstocks in place of fossil resources. To date, much effort has been devoted to the direct carbon-oxygen $(\mathrm{C}-\mathrm{O})$ bond cleavage of high-oxygen containing biogenic polyols to produce valuable chemicals by hydrogenolysis and deoxydehydration ${ }^{8,9}$. For example, there are many attempts for the selective hydrogenolysis of glycerol, facilely obtained from fats and oils, to 1,2-propanediol and 1,3-propanediol as the valuable polyester monomers and solvents using the copperand platinum-based heterogeneous catalysts, respectively ${ }^{10,11}$. On the other hand, selective cleavage of carboncarbon $(\mathrm{C}-\mathrm{C})$ bonds has not yet been widely researched despite its great potential for extending the utility of biomass-derived oxygenates to obtain the desired carbon chain length ${ }^{12-14}$. The existing $\mathrm{C}-\mathrm{C}$ bond cleavage methods include cracking, hydrocracking, decarbonylation, and decarboxylation ${ }^{15}$. However, these reactions often suffer from low selectivity toward the desired chemicals, limited substrate scope, and high reaction temperatures. Recently, decarboxylation reactions of fatty acids using $\mathrm{Ni}$ and Pd catalysts have been reported for the production of biofuels; however, these methods still require harsh reaction conditions ${ }^{16-18}$. Therefore, the development of selective and versatile $\mathrm{C}-\mathrm{C}$ bond scission catalysts able to work under milder conditions is highly desired to open new routes for industrially important chemicals from a wide range of biomass derivatives ${ }^{4}$. In this work, we found that cerium oxide-supported ruthenium nanoparticles $\left(\mathrm{Ru} / \mathrm{CeO}_{2}\right)$ efficiently promote the selective $\mathrm{C}-\mathrm{C}$ bond scission of levulinic acid (LA) to 2-butanol $(2-\mathrm{BuOH})$ in water. There are many reports on the catalytic transformation of LA to value-added C5 chemicals: e.g. $\gamma$-valerolactone $(\mathrm{GVL})^{19}$, 1,4-pentanediol $(1,4-\mathrm{PeD})^{19}$, and 2-methyltetrahydrofuran $(\mathrm{MTHF})^{20}$. However, there are fewer examples of the refinery of LA into valuable $\mathrm{C} 4$ chemicals such as 2-butanol through $\mathrm{C}-\mathrm{C}$ bond scission reactions ${ }^{21}$. The high generality of this method is demonstrated by its broad substrate scope for oxygenated compounds, where the cleavage of $\mathrm{C}-\mathrm{C}$ bonds occurs chemospecifically at positions adjacent to carboxyl, ester, and hydroxymethyl groups of oxygenated compounds (Fig. 1). Our results provide a simple and green method for the refinery of platform chemicals from biomass, which have been currently produced from petroleum feedstock.

\section{Results and Discussion}

At the outset of our catalytic studies, we chose LA as the model substrate, which is an important platform biomass-derivative leading to a variety of useful chemicals ${ }^{22,23}$. Figure 2 and Table 1 show the results of the

${ }^{1}$ Department of Materials Engineering Science, Graduate School of Engineering Science, Osaka University, 1-3 Machikaneyama, Toyonaka, Osaka, 560-8531, Japan. ${ }^{2}$ Research Center for Solar Energy Chemistry, Osaka University, 1-3 Machikaneyama, Toyonaka, Osaka, 560-8531, Japan. Correspondence and requests for materials should be addressed to K.K. (email: kaneda@cheng.es.osaka-u.ac.jp) 


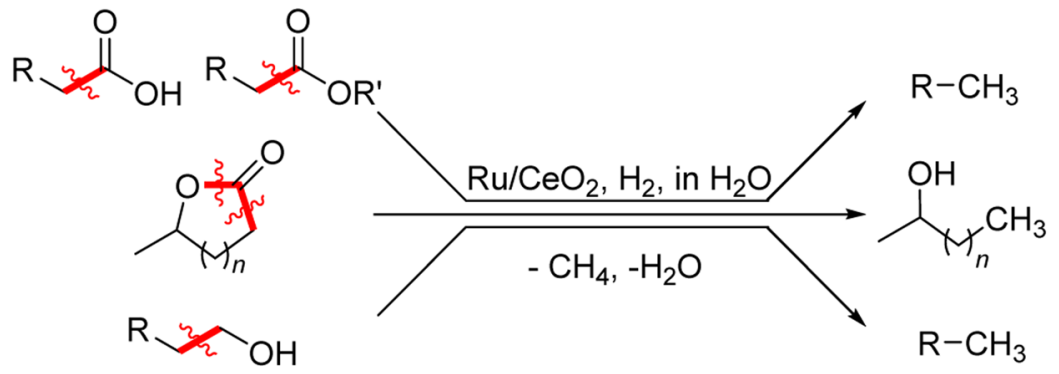

Figure 1. Reductive one-carbon scission of oxygenate compounds such as carboxylic acids, esters, lactones, and primary alcohols catalyzed by $\mathrm{Ru} / \mathrm{CeO}_{2}$ in water.

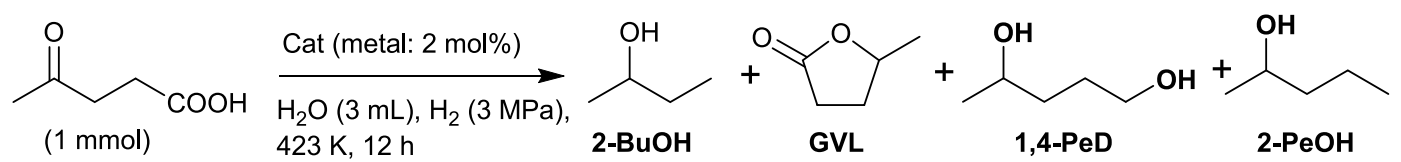

Figure 2. Reductive one-carbon scission of LA in water.

\begin{tabular}{|c|c|c|c|c|c|c|c|}
\hline \multirow[b]{2}{*}{ Entry } & \multirow[b]{2}{*}{ Catalyst } & \multirow[b]{2}{*}{ Solvent } & \multirow{2}{*}{$\begin{array}{l}\text { Conv. } \\
{[\%]^{[\mathrm{a}]}}\end{array}$} & \multicolumn{4}{|c|}{ Yield [\%] ${ }^{[\mathrm{a}]}$} \\
\hline & & & & 2-BuOH & GVL & 1,4-PeD & 2-PeOH \\
\hline 1 & $\mathrm{Ru} / \mathrm{CeO}_{2}$ & $\mathrm{H}_{2} \mathrm{O}$ & $>99$ & 85 & 0 & 0 & 5 \\
\hline $2^{[\mathrm{b}]}$ & $\mathrm{Ru} / \mathrm{CeO}_{2}$ & $\mathrm{H}_{2} \mathrm{O}$ & $>99$ & 81 & 0 & 0 & 6 \\
\hline 3 & $\mathrm{Ru} / \mathrm{CeO}_{2}$ & 2-PrOH & $>99$ & 5 & 69 & 23 & 0 \\
\hline 4 & $\mathrm{Ru} / \mathrm{CeO}_{2}$ & THF & $>99$ & 4 & 70 & 23 & 0 \\
\hline 5 & $\mathrm{Ru} / \mathrm{CeO}_{2}$ & DME & $>99$ & 0 & 77 & 9 & 0 \\
\hline 6 & $\mathrm{Ru} / \mathrm{HAP}$ & $\mathrm{H}_{2} \mathrm{O}$ & $>99$ & 59 & 16 & 3 & 11 \\
\hline $7^{[c]}$ & $\mathrm{Ru} / \mathrm{C}$ & $\mathrm{H}_{2} \mathrm{O}$ & $>99$ & 58 & 0 & 0 & 27 \\
\hline 8 & $\mathrm{Ru} / \mathrm{ZrO}_{2}$ & $\mathrm{H}_{2} \mathrm{O}$ & $>99$ & 57 & 16 & 3 & 8 \\
\hline 9 & $\mathrm{Ru} / \mathrm{TiO}_{2}$ & $\mathrm{H}_{2} \mathrm{O}$ & $>99$ & 45 & 29 & 5 & 10 \\
\hline 10 & $\mathrm{Ru} / \mathrm{La}(\mathrm{OH})_{3}$ & $\mathrm{H}_{2} \mathrm{O}$ & $>99$ & 34 & 27 & 16 & 2 \\
\hline 11 & $\mathrm{Ru} / \mathrm{HT}$ & $\mathrm{H}_{2} \mathrm{O}$ & $>99$ & 17 & 38 & 4 & 1 \\
\hline 12 & $\mathrm{Ru} / \mathrm{SiO}_{2}$ & $\mathrm{H}_{2} \mathrm{O}$ & $>99$ & 6 & 81 & 11 & 1 \\
\hline 13 & $\mathrm{Ru} / \mathrm{MgO}$ & $\mathrm{H}_{2} \mathrm{O}$ & $>99$ & 6 & 50 & 4 & 0 \\
\hline 14 & $\mathrm{Ru} / \mathrm{Al}_{2} \mathrm{O}_{3}$ & $\mathrm{H}_{2} \mathrm{O}$ & $>99$ & 1 & 92 & 5 & 0 \\
\hline 15 & $\mathrm{Rh} / \mathrm{CeO}_{2}$ & $\mathrm{H}_{2} \mathrm{O}$ & $>99$ & $<1$ & 66 & 2 & 0 \\
\hline 16 & $\mathrm{Pd} / \mathrm{CeO}_{2}$ & $\mathrm{H}_{2} \mathrm{O}$ & $>99$ & 0 & 77 & 1 & 0 \\
\hline 17 & $\mathrm{Ir} / \mathrm{CeO}_{2}$ & $\mathrm{H}_{2} \mathrm{O}$ & $>99$ & 0 & 71 & 2 & 0 \\
\hline 18 & $\mathrm{Pt} / \mathrm{CeO}_{2}$ & $\mathrm{H}_{2} \mathrm{O}$ & $>99$ & 0 & 68 & 4 & 0 \\
\hline $19^{[\mathrm{d}]}$ & $\mathrm{CeO}_{2}$ & $\mathrm{H}_{2} \mathrm{O}$ & 7 & 0 & 0 & 0 & 0 \\
\hline
\end{tabular}

Table 1. Carbon-carbon scission of LA using various catalysts. ${ }^{[a]}$ Analyzed by GC-MS using an internal standard. ${ }^{[b]} \mathrm{A} 50 \mathrm{mmol}-\mathrm{scale}$ reaction (see Supplementary Information for details). ${ }^{[\mathrm{c}]} \mathrm{Ru} / \mathrm{C}$ (Ru $5 \mathrm{wt} \%$, Wako Pure Chemicals) was used. 2-Methyltetrahydrofurane was formed in $8 \%$ yield. ${ }^{[\mathrm{d}]} \mathrm{CeO}_{2} 0.1 \mathrm{~g}$ was used.

hydrogenative decarboxylation of LA using various supported metal catalysts at $423 \mathrm{~K}$ and $3 \mathrm{MPa}$ of $\mathrm{H}_{2}$. It was found that $\mathrm{Ru} / \mathrm{CeO}_{2}$ efficiently afforded 2- $\mathrm{BuOH}$ in water, currently produced from 1-butene and 2-butene, as the major product in $85 \%$ yield (entry 1 ). The LA consumption and the products formation profiles shown in Figure S1 revealed that conversion of LA rapidly completed within 1 hour, and GVL and 1,4-PeD were formed for 1 hour and three hours, respectively. The yield of $2-\mathrm{BuOH}$ drastically increased after 3 hours duration and the yield reached to $85 \%$ after 12 hours with the complete consumption of GVL and 1,4-PeD. The gas chromatography analysis of the gaseous phase after the 12 hours reaction clearly evidenced the formation of $\mathrm{CH}_{4}$, while $\mathrm{CO}$ and $\mathrm{CO}_{2}$ were not detected (Figure S2). These results clearly support that both GVL and 1,4-PeD are not side products but the intermediate products leading to $2-\mathrm{BuOH}$ (vide infra).

The promising catalysis of $\mathrm{Ru} / \mathrm{CeO}_{2}$ was compared with those of the $\mathrm{Ru}$-based heterogeneous catalysts. $\mathrm{Ru} /$ $\mathrm{HAP}$ (hydroxyapatite), $\mathrm{Ru} / \mathrm{C}$ (activated carbon), $\mathrm{Ru} / \mathrm{ZrO}_{2}, \mathrm{Ru} / \mathrm{TiO}_{2}$, and $\mathrm{Ru} / \mathrm{La}(\mathrm{OH})_{3}$ gave moderate yields of 2- $\mathrm{BuOH}$ (entries 6-10) and GVL, 1,4-PeD, and 2-PeOH were obtained as the by-products. Ru/HT (hydrotalcite), $\mathrm{Ru} / \mathrm{SiO}_{2}, \mathrm{Ru} / \mathrm{MgO}$, and $\mathrm{Ru} / \mathrm{Al}_{2} \mathrm{O}_{3}$ returned low yields of $2-\mathrm{BuOH}$ and $\mathrm{GVL}$ was the major product (entries 


\begin{tabular}{|c|c|c|c|c|c|c|c|}
\hline entry & substrate & main product & yield [\%] $^{[\mathrm{a}]}$ & entry & substrate & main product & yield [\%] ${ }^{[a]}$ \\
\hline \multicolumn{2}{|c|}{ carboxylic acids } & & & & polyols & & \\
\hline 1 & & & 85 & 15 & & & 72 \\
\hline 2 & & & 81 & 16 & & & 72 \\
\hline 3 & & & $(97)$ & 17 & & & 97 \\
\hline 4 & & & 87 & 18 & & & 92 \\
\hline 5 & & & 75 & 19 & & & 92 \\
\hline 6 & & & 76 & 20 & & & $(92)$ \\
\hline 7 & & & 82 & 21 & & & 93 \\
\hline 8 & & & 82 & & mono-o & & \\
\hline 9 & & & 82 & 22 & & & 89 \\
\hline 10 & & & (96) & 23 & & & 95 \\
\hline 11 & & & 68 & 24 & & & 97 \\
\hline 12 & lactones & & 83 & 25 & & & 93 \\
\hline 13 & & & 86 & 26 & & & 99 \\
\hline 14 & & & 80 & & & & \\
\hline
\end{tabular}

Table 2. Selective C-C bond scission of various oxygenates catalyzed by $\mathrm{Ru} / \mathrm{CeO}_{2}$. ${ }^{\mathrm{a}}$ Determined by GC-MS using an internal standard technique. The values in parentheses are the isolated yields. See Table S4 and Supplementary Information for details.

11-14) under the similar conditions shown in entry 1 . Among the $\mathrm{CeO}_{2}$-supported noble metal catalysts, $\mathrm{Ru} /$ $\mathrm{CeO}_{2}$ afforded the highest yield of 2- $\mathrm{BuOH}$, while $\mathrm{Rh}$, Pd, Ir, and $\mathrm{Pt}$ on $\mathrm{CeO}_{2}$ gave much lower yields while GVL was obtained as the major product in 66-77 yields (entry 1 vs. 15-18). The $\mathrm{CeO}_{2}$ support did not exhibit any catalytic activity by itself (entry 19). Interestingly, water was found to the best solvent for the production of 2-BuOH; the use of organic solvents such as 2-PrOH (2-propanol), THF (tetrahydrofuran), and DME (dimethoxyethane) resulted in low yields of $2-\mathrm{BuOH}$ (entry 1 vs. 3-5). These results clearly suggest that the combination of $\mathrm{Ru}, \mathrm{CeO}_{2}$, and water is indispensable to achieve the selective transformation of LA into 2-BuOH. To the best of our knowledge, this is the first report on the highly selective production of 2-BuOH from LA (Table S1). Furthermore, $\mathrm{Ru} /$ $\mathrm{CeO}_{2}$ worked in a preparative scale reaction; $50 \mathrm{mmol}$ of LA $(5.8 \mathrm{~g})$ affording $81 \%$ yield of $2-\mathrm{BuOH}$ (entry 2). After the reaction, the $\mathrm{Ru} / \mathrm{CeO}_{2}$ catalyst was easily separated from the reaction mixture by centrifugation. The $\mathrm{Ru} / \mathrm{CeO}_{2}$ catalyst could be used for 5 consecutive runs without appreciable loss of the activity and selectivity (Table S6). The ICP-AES analysis clearly showed that any metal leaching did not occur during the reaction, confirming the robustness of the $\mathrm{Ru} / \mathrm{CeO}_{2}$ catalyst. 


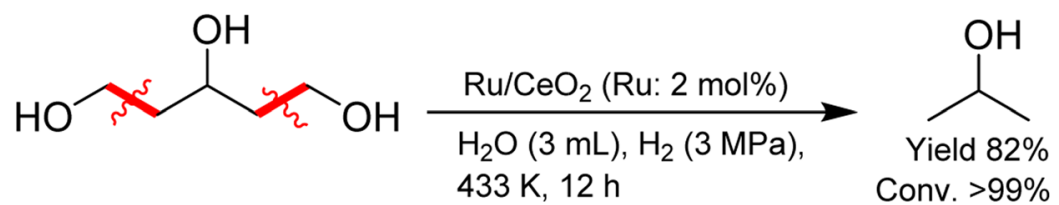

Figure 3. Double dehydroxymethylation of 1,3,5-pentanetriol to 2-propanol.

Encouraged by the above promising catalysis of $\mathrm{Ru} / \mathrm{CeO}_{2}$, we applied this catalyst for the selective $\mathrm{C}-\mathrm{C}$ bond scission of various biogenic oxygenates (Table 2 , entries $1-5,7-10,12,15-17,25,26)$. Notably, this catalyst system provided new eight routes for common industrial chemicals from biogenic carboxylic acids, esters, and polyols (entries 2, 5, 7-9, 15-17). Lignocellulose-derived 3-hydroxybutyric acid and its methyl ester selectively afforded 2 - $\mathrm{PrOH}$ in $81 \%$ and $82 \%$ yield, respectively (entries 2 and 9), while lignin-derived 4 -hydroxybenzoic acid provided $75 \%$ yield of cyclohexanol ${ }^{24}$, which is currently manufactured from fossil resources (entry 5$)^{25}$. Methyl and $n$-butyl levulinate selectively afforded $2-\mathrm{BuOH}$ in $82 \%$ yield, respectively (entries 7 and 8$)^{26}$. Biogenic polyols were also transformed by the present catalyst system. Reaction of 1,4-PeD, obtained from $\mathrm{LA}$, afforded 2- $\mathrm{BuOH}$ in high yield (entry 17). In the case of $\alpha, \beta, \omega$-triols of 1,2,4-butanetriol and 1,2,6-hexanetriol, the $\mathrm{C}$-C bond scission selectively occurred at the primary hydroxy group distant from the 1,2-dihydroxy moiety and the corresponding 1,2-propanediol and 1,2-pentanediol were obtained in $72 \%$ yield (entries 15 and 16). Thus, new routes for common industrial chemicals from biomass-derived oxygenates were successfully established with this $\mathrm{Ru} / \mathrm{CeO}$ catalyst. Furthermore, $\mathrm{Ru} / \mathrm{CeO}_{2}$ afforded higher yields of valuable chemicals for existing transformations of GVL (entry 12), stearic acid (entry 3), lauric acid (entry 4), and their derivatives (entries 10, 25, and 26), compared to the reported catalytic systems which result in lower yields and require organic solvents and/or harsher reaction conditions (Tables S2 and S3).

The high generality of this selective $\mathrm{C}-\mathrm{C}$ bond scission reaction was also demonstrated using various oxygenated compounds, as listed in Table 2 (entries 6, 11, 13, 14, 18-24). For example, four- and six-membered lactones selectively afforded secondary alcohols in high yield (entries 13 and 14). Cyclohexane was obtained in excellent yield from benzyl alcohol and cyclohexylmethanol (entries 22 and 23) ${ }^{27}$. In the case of diols, the chemospecific cleavage occurred at the $\mathrm{C}-\mathrm{C}$ bond adjacent to the primary hydroxyl group, while the secondary and tertiary hydroxyl moieties remained intact (entries 18-21). Such a characteristic feature of the $\mathrm{Ru} / \mathrm{CeO}_{2}$ catalyst regarding the selectivity toward primary hydroxyl groups was confirmed in the double dehydroxymethylation of 1,3,5-pentanetriol to $2-\mathrm{PrOH}$ (Fig. 3). Thus, the $\mathrm{Ru} / \mathrm{CeO}_{2}$ catalyst is successfully applicable to the $\mathrm{C}-\mathrm{C}$ bond cleavage of a wide variety of oxygenates not only with short carbon chains but also with long ones and/or aromatic groups.

In order to clarify the origin of the unique catalysis of $\mathrm{Ru} / \mathrm{CeO}_{2}$ in water, physicochemical analyses of the used $\mathrm{Ru} / \mathrm{CeO}_{2}$ catalyst were carried out. In situ X-ray powder diffraction (XRD) pattern of the used $\mathrm{Ru} / \mathrm{CeO}_{2}$ catalyst revealed that the $\mathrm{CeO}_{2}$ support was reductively hydrothermalized during the reaction to form $\mathrm{Ce}(\mathrm{OH})_{3}$ (Figure S3,b vs.c) ${ }^{28,29}$. Furthermore, no diffraction peaks derived from crystalline Ru oxide and Ru metal were observed in the fresh and the used catalysts, suggesting the high dispersity of Ru species, respectively. The Ru K-edge X-ray absorption analysis revealed that the Ru oxide in the fresh catalyst was reduced under the operating conditions to afford metallic Ru nanoparticles (RuNPs) with a mean diameter of ca $3 \mathrm{~nm}$, which agreed well with the sizes obtained from TEM and CO adsorption (Figure S6 and Table S5). The $\mathrm{Ce}_{3}$-edge XANES analysis also confirmed the complete reduction of $\mathrm{Ce}^{4+}$ to $\mathrm{Ce}^{3+}$ species under the reaction conditions (Figure S5). On the other hand, neither the $\mathrm{Ru} / \mathrm{CeO}_{2}$ catalysts used in organic solvents nor the $\mathrm{CeO}_{2}$ sample without $\mathrm{Ru}$ used in water revealed that $\mathrm{CeO}_{2}$ was reduced to $\mathrm{Ce}(\mathrm{OH})_{3}$ during the reaction. In accordance to the change of the chemical state of $\mathrm{Ru} / \mathrm{CeO}_{2}$, the FE-SEM analysis also showed the morphology change of the particular $\mathrm{CeO}_{2}$ to the nanorods (Figure S6a,b). The Ru dispersion was strongly affected by the support materials and highly dispersed RuNPs were formed only on $\mathrm{CeO}_{2}$ (Table S7). Conclusively, highly dispersed RuNPs supported on $\mathrm{Ce}(\mathrm{OH})_{3}$ were formed during the reaction in water after the reductive hydrothermal treatment of $\mathrm{Ru} / \mathrm{CeO}_{2}$.

Taking into account of the above results of the catalytic reactions and the characterization, a reaction pathway for the $\mathrm{C}-\mathrm{C}$ bond scission of LA to $2-\mathrm{BuOH}$ through multiple catalysis by $\mathrm{RuNPs}$ and $\mathrm{Ce}(\mathrm{OH})_{3}$ is thus proposed (Figure $\mathrm{S} 7)^{16,17,30}$. The keto function of LA is readily hydrogenated by RuNPs to give 4-hydroxypentanoic acid $(\mathrm{HPA})^{31,32}$. Then, HPA is further reduced to 4 -hydroxypentanal, followed by decarbonylation affords $2-\mathrm{BuOH}$ and $\mathrm{Ru}-\mathrm{CO}$ species $^{32}$. The resulting $\mathrm{CO}$ on RuNPs is hydrogenated to $\mathrm{CH}_{4}$ (Figure S2) ${ }^{33}$, completing the catalytic cycle. GVL and 1,4-PeD are reversibly formed as intermediates from HPA and 4-hydroxypentanal, respectively ${ }^{21}$. Hydrolysis of lactone of GVL to HPA is mediated by $\mathrm{Ce}(\mathrm{OH})_{3}{ }^{34,35}$, and 1,4-PeD is dehydrogenated by RuNPs with assistance of $\mathrm{Ce}(\mathrm{OH})_{3}$ at the primary hydroxy group to form 4-hydroxyaldehyde, thereby entering the catalytic cycle $^{36-38}$. Also, the $\mathrm{C}-\mathrm{C}$ bond scissions of esters including lactones and primary alcohols in Table 2 proceed similar way with the cases of GVL and 1,4-PeD. Overall, RuNPs mediate five successive reactions: reduction of both keto and carboxyl functions, dehydrogenation of a primary hydroxy group, decarbonylation of an aldehyde, and hydrogenation of $\mathrm{CO}$. $\mathrm{Ce}(\mathrm{OH})_{3}$ acts as a base to promote (a) the reduction of a carboxyl function, (b) dehydrogenation of a primary hydroxyl group, and (c) hydrolysis of GVL to HPA. Such cooperative catalysis between RuNPs and $\mathrm{Ce}(\mathrm{OH})_{3}$ leads to the excellent generality of this selective one-carbon scission of the oxygenated compounds as shown in Table 2. The drastic support effects of Ru catalysts on the 2-BuOH yields were attributed not only to the basicity of the supports, but also to the dispersity of Ru species (Tables 1 and S7). 
In summary, selective hydrogenative $\mathrm{C}-\mathrm{C}$ bond scission over $\mathrm{C}-\mathrm{O}$ bond of biogenic oxygenates to valuable chemicals was achieved with a $\mathrm{Ru} / \mathrm{CeO}_{2}$ catalyst in water. The high versatility of the present catalytic system allows the transformation of a variety of carboxylic acids, esters, lactones, and polyols bearing primary hydroxy groups, establishing eight new biorefinery routes. Both the RuNPs and in situ generated $\mathrm{Ce}(\mathrm{OH})_{3}$ in water are crucial for the highly selective $\mathrm{C}-\mathrm{C}$ bond cleavage of the presented biomass-derived oxygenates and a wide range of other oxygenated compounds.

\section{Methods}

Catalyst preparation. The $\mathrm{Ru} / \mathrm{CeO}_{2}$ catalyst was prepared by the deposition-precipitation method. $\mathrm{CeO}_{2}$ $(1 \mathrm{~g})$ was added to $50 \mathrm{~mL}$ of an aqueous solution of $\mathrm{RuCl}_{3}(4 \mathrm{mM})$. After stirring for $1 \mathrm{~h}, 3 \mathrm{~mL}$ of an aqueous $\mathrm{NH}_{3}$ solution $(28 \%)$ was added to the reaction mixture, which was further stirred at $298 \mathrm{~K}$ for $12 \mathrm{~h}$. The obtained slurry was filtered and washed with deionized water and dried at $383 \mathrm{~K}$ for $12 \mathrm{~h}$, and finally calcined at $573 \mathrm{~K}$ for $3 \mathrm{~h}$ under static air atmosphere to obtain $\mathrm{Ru} / \mathrm{CeO}_{2}$ as a blown powder ( $\mathrm{Ru}: 2 \mathrm{wt} \%$ ). Other metal oxide-supported $\mathrm{Ru}$ catalysts $\left(\mathrm{Ru} / \mathrm{ZrO}_{2}, \mathrm{Ru} / \mathrm{TiO}_{2}, \mathrm{Ru} / \mathrm{MgO}\right.$, and $\left.\mathrm{Ru} / \mathrm{Al}_{2} \mathrm{O}_{3}\right)$ were also prepared by the deposition-precipitation method.

Typical reaction procedure. The reactions with levulinic acid were carried out in a $50 \mathrm{~mL}$ stainless steel autoclave equipped with a Teflon vessel. The reactor was charged with $1 \mathrm{mmol}$ of levulinic acid, $0.1 \mathrm{~g}$ of $\mathrm{Ru} / \mathrm{CeO}_{2}$ catalyst, and $3 \mathrm{~mL}$ of water; a Teflon ${ }^{\oplus}$-coated magnetic stir bar was also added. The reactor was sealed, purged three times with $\mathrm{H}_{2}$, then pressurized to $3 \mathrm{MPa}$, heated to $423 \mathrm{~K}$, and stirred at $700 \mathrm{rpm}$ for $12 \mathrm{~h}$. After the reaction, the autoclave was cooled in an ice-water bath and the hydrogen gas was carefully released. The solid catalyst was separated by centrifugation and the reaction mixture was quantitatively analyzed by gas chromatography-mass spectrometry using internal standard method.

\section{References}

1. Sun, D. et al. Production of C4 and C5 alcohols from biomass-derived materials. Green Chem. 18, 2579-2597 (2016).

2. Wu, K. et al. Heterogeneous catalytic conversion of biobased chemicals into liquid fuels in the aqueous phase. ChemSusChem $\mathbf{9}$, 1355-1385 (2016).

3. Besson, M. L., Gallezot, P. \& Pinel, C. Conversion of biomass into chemicals over metal catalysts. Chem. Rev. 114, 1827-1870 (2014).

4. Bozell, J. J. \& Petersen, G. R. Technology development for the production of biobased products from biorefinery carbohydrates-the US Department of Energy's “Top 10” revisited. Green Chem. 12, 539-554 (2010).

5. Corma, A., Iborra, S. \& Velty, A. Chemical routes for the transformation of biomass into chemicals. Chem. Rev. 107, 2411-2502 (2007).

6. Verma, S., Baig, R. B. N., Nadagouda, M. N., Len, C. \& Varma, R. S. Sustainable pathway to furanics from biomass via heterogeneous organo-catalysis. Green Chem. 19, 164-168 (2017).

7. Tadele, K., Verma, S., Gonzalez, M. A. \& Varma, R. S. A sustainable approach to empower the bio-based future: upgrading of biomass via process intensification. Green Chem. 19, 1624-1627 (2017).

8. Robinson, A. M., Hensley, J. E. \& Medlin, J. W. Bifunctional catalysts for upgrading of biomass-derived oxygenates: a review. ACS Catal. 6, 5026-5043 (2016).

9. Nakagawa, Y., Liu, S., Tamura, M. \& Tomishige, K. Catalytic total hydrodeoxygenation of biomass-derived polyfunctionalized substrates to alkanes. ChemSusChem 8, 1114-1132 (2015).

10. Mizugaki, T., Arundhathi, R., Mitsudome, T., Jitsukawa, K. \& Kaneda, K. Selective hydrogenolysis of glycerol to 1,2-propanediol using heterogeneous copper nanoparticle catalyst derived from Cu-Al hydrotalcite. Chem. Lett. 42, 729-731 (2013).

11. Arundhathi, R., Mizugaki, T., Mitsudome, T., Jitsukawa, K. \& Kaneda, K. Highly selective hydrogenolysis of glycerol to 1,3-propanediol over a boehmite-supported platinum/tungsten catalyst. Chem Sus Chem 6, 1345-1347 (2013).

12. Saidi, M. et al. Upgrading of lignin-derived bio-oils by catalytic hydrodeoxygenation. Energy Environ. Sci. 7, 103-129 (2014).

13. Bulushev, D. A. \& Ross, J. R. H. Catalysis for conversion of biomass to fuels via pyrolysis and gasification: A review. Catal. Today 171, $1-13$ (2011).

14. Stocker, M. Biofuels and biomass-to-liquid fuels in the biorefinery: catalytic conversion of lignocellulosic biomass using porous materials. Angew. Chem. Int. Ed. 47, 9200-9211 (2008).

15. Ruddy, D. A. et al. Recent advances in heterogeneous catalysts for bio-oil upgrading via "ex situ catalytic fast pyrolysis": catalyst development through the study of model compounds. Green Chem. 16, 454-490 (2014).

16. Hachemi, I. et al. Comparative study of sulfur-free nickel and palladium catalysts in hydrodeoxygenation of different fatty acid feedstocks for production of biofuels. Catal. Sci. Technol. 6, 1476-1487 (2016).

17. Peng, B., Yuan, X., Zhao, C. \& Lercher, J. A. Stabilizing catalytic pathways via redundancy: selective reduction of microalgae oil to alkanes. J. Am. Chem. Soc. 134, 9400-9405 (2012).

18. Guo, J.-H. et al. Catalytic conversion of Jatropha oil to alkanes under mild conditions with a Ru/La $(\mathrm{OH})_{3}$ catalyst. Green Chem. 17, 2888-2895 (2015).

19. Mizugaki, T. et al. Selective hydrogenation of levulinic acid to 1,4-pentanediol in water using a hydroxyapatite-supported Pt-Mo bimetallic catalyst. Green Chem. 17, 5136-5139 (2015).

20. Mizugaki, T. et al. One-pot transformation of levulinic acid to 2 -methyltetrahydrofuran catalyzed by $\mathrm{Pt}-\mathrm{Mo} / \mathrm{H}-\beta$ in water. $A C S$ Sustainable Chem. Eng. 4, 682-685 (2016).

21. Cabiac, A., Guillon, E., Pinel, C., Corbeldemailly, L. \& Besson, M. Procede de production d'alcools per hydrogenation catalytique d'acide levulinique en une etape. Franch patent FR3008970 (2015).

22. Antonetti, C., Licursi, D., Fulignati, S., Valentini, G. \& Galletti, A. M. R. New frontiers in the catalytic synthesis of levulinic acid: From sugars to raw and waste biomass as starting feedstock. Catalysts 6, 196 (2016).

23. Pileidis, F. D. \& Maria-Magdalena, Titirici Levulinic acid biorefineries: New challenges for efficient utilization of biomass. ChemSusChem 9, 562-582 (2016).

24. Terashima, N., Mori, I. \& Kanda, T. Biosynthesis of p-hydroxybenzoic acid in polar lignin. Phytochemistry 14, 1991-1992 (1975).

25. Musser, M. T. Cyclohexanol and cyclohexanone. Ullmann's Encyclopedia of Industrial Chemistry, 2011. https://doi. org/10.1002/14356007.a08_217.pub2.

26. Démolis, A., Essayem, N. \& Rataboul, F. Synthesis and applications of alkyl levulinates. ACS Sustainable Chem. Eng. 2, 1338-1352 (2014).

27. Modak, A., Naveen, T. \& Maiti, D. An efficient dehydroxymethylation reaction by a palladium catalyst. Chem. Commun. 49, 252-254 (2013). 
28. Wang, L., Luan, Q., Yang, D., Yao, X. \& Zhou, K. Strong electron-conjugation interaction facilitates electron transfer of hemoglobin by $\mathrm{Ce}(\mathrm{OH})_{3}$ nanorods. RSC Adv. 3, 6339-6342 (2013).

29. Tang, C., Bando, Y., Liu, B. \& Golberg, D. Cerium oxide nanotubes prepared from cerium hydroxide nanotubes. Adv. Mater. 17, 3005-3009 (2005).

30. Chen, L. et al. Mechanistic insights into the effects of support on the reaction pathway for aqueous-phase hydrogenation of carboxylic acid over the supported Ru catalysts. Appl. Catal. A 478, 117-128 (2014).

31. Vohs, J. M. Site requirements for the adsorption and reaction of oxygenates on metal oxide surfaces. Chem. Rev. 113, 4136-4163 (2013).

32. Pritchard, J., Filonenko, G. A., van Putten, R., Hensen, E. J. \& Pidko, E. A. Heterogeneous and homogeneous catalysis for the hydrogenation of carboxylic acid derivatives: history, advances and future directions. Chem. Soc. Rev. 44, 3808-3833 (2015).

33. Abdel-Mageed, A. M., Eckle, S. \& Behm, R. J. High selectivity of supported Ru catalysts in the selective CO methanation-water makes the difference. J. Am. Chem. Soc. 137, 8672-8675 (2015).

34. Li, J. et al. Pressure regulations on the surface properties of $\mathrm{CeO}_{2}$ nanorods and their catalytic activity for $\mathrm{CO}$ oxidation and nitrile hydrolysis reactions. ACS Appl Mater Interfaces 8, 22988-22996 (2016).

35. Wang, Y. et al. Heterogeneous ceria catalyst with water-tolerant Lewis acidic sites for one-pot synthesis of 1,3-diols via Prins condensation and hydrolysis reactions. J. Am. Chem. Soc. 135, 1506-1515 (2013).

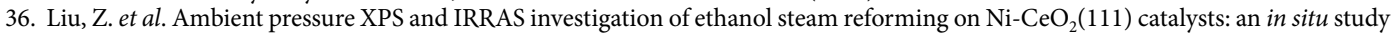
of C-C and O-H bond scission. Phys. Chem. Chem. Phys. 18, 16621-16628 (2016).

37. Motokura, K. et al. A ruthenium-grafted hydrotalcite as a multifunctional catalyst for direct $\alpha$-alkylation of nitriles with primary alcohols. J. Am. Chem. Soc. 126, 5662-5663 (2004).

38. Yamaguchi, K., Mori, K., Mizugaki, T., Ebitani, K. \& Kaneda, K. Creation of a monomeric Ru species on the surface of hydroxyapatite as an efficient heterogeneous catalyst for aerobic alcohol oxidation. J. Am. Chem. Soc. 122, 7144-7145 (2000).

\section{Acknowledgements}

This study was supported by JSPS KAKENHI (16K14479, 26105003, 26289303, 16K14480, 17H03456, and 17H03457). The authors would like to thank Dr. Tetsuo Honma and Dr. Toshiaki Ina (JASRI) for the XAFS experiments (2015B1571, 2016A1525, 2016A1103, 2016B1546, 2016B1851 and 2017A1582). The TEM experiments were carried out at a facility in the Research Center for Ultrahigh Voltage Electron Microscopy, Osaka University.

\section{Author Contributions}

K.K. supervised the research. T. Miz. wrote the paper and coordinated all the experimental work. K.T. and T. Miz. performed the experiments. Z.M., T. Mit, and K.J. discussed the experiments and results. All the authors commented critically on the manuscript and approved the final manuscript.

\section{Additional Information}

Supplementary information accompanies this paper at https://doi.org/10.1038/s41598-017-14373-1.

Competing Interests: The authors declare that they have no competing interests.

Publisher's note: Springer Nature remains neutral with regard to jurisdictional claims in published maps and institutional affiliations.

(c) (i) Open Access This article is licensed under a Creative Commons Attribution 4.0 International License, which permits use, sharing, adaptation, distribution and reproduction in any medium or format, as long as you give appropriate credit to the original author(s) and the source, provide a link to the Creative Commons license, and indicate if changes were made. The images or other third party material in this article are included in the article's Creative Commons license, unless indicated otherwise in a credit line to the material. If material is not included in the article's Creative Commons license and your intended use is not permitted by statutory regulation or exceeds the permitted use, you will need to obtain permission directly from the copyright holder. To view a copy of this license, visit http://creativecommons.org/licenses/by/4.0/.

(C) The Author(s) 2017 